\title{
Pronunciation Problems: A Case Study of English Language Students at Sudan University of Science and Technology
}

\author{
Elkhair Muhammad Idriss Hassan ${ }^{1}$ \\ ${ }^{1}$ English Language Department, Al-Farabi Private College, Riyadh, KSA \\ Correspondence: Elkhair Muhammad Idriss Hassan, English Language Department, Al-Farabi Private College, \\ Riyadh, KSA. Tel: 966-50-892-3934.E-mail: elkhairmidriss@yahoo.co.uk
}

\author{
Received: August 31, 2014 Accepted: October 15, 2014 Online Published: November 25, 2014 \\ doi:10.5539/ells.v4n4p31 URL: http://dx.doi.org/10.5539/ells.v4n4p31
}

\begin{abstract}
This study investigates the problems in English pronunciation experienced by learners whose first language is Sudanese Spoken Arabic. In other words to find the problematic sounds and the factors that cause these problems. Then find some techniques that help the Sudanese Students of English improve their pronunciation. The subjects for the study were fifty students from University of Sudan of Science and Technology (SUST), and thirty university teachers of English language from the same university.

The instruments used for collecting the data were observation, recordings and a structured questionnaire. The data collected were analyzed both statistically and descriptively. The findings of the study revealed that Sudanese Students of English whose language background is Sudanese Spoken Arabic, had problems with the pronunciation of English vowels that have more than one way of pronunciation in addition to the consonant sound contrasts e.g. $/ \mathrm{z} /$ and $/ \mathrm{\delta} /, / \mathrm{s} /$ and $/ \theta /, / \mathrm{b} /$ and $/ \mathrm{p} /, / \mathrm{J} /$ and $/ \mathrm{t} \int /$. Based on the findings, the study concluded that factors such as Interference, the differences in the sound system in the two languages, inconsistency of English sounds and spelling militate against Sudanese Students of English (SSEs) competence in pronunciation.
\end{abstract}

Keywords: English pronunciation, problematic sound, Sudanese university student, mother tongue

\section{Introduction}

All around the world, there are a lot of people with strong desire to learn and speak English with correct pronunciation. In Sudan, there is a large number of interested groups in the subject; among them are the students of English language at Sudan University of Science and Technology. However, there are many barriers that hinder them to speak with good English pronunciation.

Many studies have demonstrated that the errors made by the speakers of other languages, who speak English, are something systematic rather than random. Moosa (1972) and Homeidan (1984) demonstrated that Arab students face problem in the pronunciation of sounds which the students are not familiar with

e.g. /v/, /p/, /y/ (Ronald Carter and David Nunan, 2001) (O’Connor, 2003) noted that the errors of pronunciation that learners of English from different language backgrounds make are systematic and not accidental. So they concluded that the main problem of the speakers of. other languages who speak English, is substitution of sounds i.e. they substitute the sounds that they don't have in their native language, with other sounds which are close to them in the place of articulation e.g. they replace $/ \mathrm{p} /$ with $/ \mathrm{b} /, / \theta / \mathrm{with} / \mathrm{s} /$ etc.

Although the same problem exists in the pronunciation of most of the Sudanese Students of English (SSEs), all the studies above were done outside Sudan e.g. for speakers of German, Italian, Spanish...etc. On the other hand, some studies have been conducted as mentioned above, but on the Arab student's e.g. for the students of English in Saudi Arabia .So that is why this research was intended to fill a certain gap. Thus, perhaps mispronunciation of sounds replacements of problematic sounds is explored. The research is seeking to study such problems of pronunciation e.g. the mispronunciation of some sounds and the shifting of particular sounds with others and to try to find what are the exact reasons for such errors i.e. are these errors related to the mother tongue interference, sound system differences between the native and the foreign language, moreover to study the influence of spelling on the pronunciation, then see to what extent the inconsistency of some English sounds affects on the pronunciation. So this study is an attempt to study such problems in a Sudanese context because substitution of sounds such as $/ \theta /$, /ð/, $/ \mathrm{p} /$ is expected in the pronunciation of many Sudanese students of English, this is because the students don't have 
such sounds in their mother tongue language i.e. (Sudanese Spoken Arabic). The importance of this study comes from the perspective that all the previous studies, addressed the problem among speakers of European languages such as German,

Spanish, Italian, Portuguese etc. and Asian languages e. g. Chinese and Thai. There are also some studies on pronunciation errors among speakers of Arabic. So this study is discussing the same problem, but for the speakers of Sudanese Spoken Arabic as a form of Arabic in Sudan. The study also aims at helping the Sudanese students of English improve their pronunciation using the modern techniques and aids in learning language e.g. internet, audio aids such as (CDs, tapes, and TV).

\section{Statement of the Problem}

A close observation of students at (SUST) disclosed that students confuse the pronunciation of some set of words e.g. most of the English words that have sounds, which do not exist in Sudanese Spoken Arabic e.g. /p/ in "experience" $/ \theta /$ in "thank" and $/ \delta /$ in "this". It was also observed that students do not differentiate between some vowel sounds which have more than one way of pronunciation e.g. the vowel in "mat" and "mate".

The researcher spent many days at (SUST) observing the pronunciation of English words by the students at (SUST) and the result of this observation at the university is twofold; first, it was

noticed that the students have problems in the pronunciation of some English sounds for instance they confuse the contrast sounds e.g. here are some words and how the students pronounce them next to each word (service/servais/, document/document/, 'women'/wumen/, 'obstacle'/obsteikl/, 'performance' /pə:fo:mans/ so in the first word they used the long form instead of short form, in the second word they used $/ \mathrm{u} /$ instead of $/ \mathrm{ju} /$, in the word women they used $/ \mathrm{u} /$ instead of $/ \mathrm{i} /$ in the word 'performance' they pronounced it with long vowel /a:/ instead of short one $\mathrm{l} / \mathrm{/}$. So we find that they confuse different pronunciations of each vowel as if there is only one pronunciation for each sound according to their knowledge.

Second, is that they have some errors with some consonants that do not exist in Sudanese Spoken Arabic e.g. / $\theta$ ð $\mathrm{p} \mathrm{v} / \mathrm{so}$ they replace them with /s z b f/.

During the listening of the SSEs pronunciation of English words the researcher found that they pronounce some words with mistakes e.g. they don't differentiate between (s-sound and $\theta$-sound) so they usually use $/ \mathrm{s} /$ instead of $/ \theta /$ if we ask them to pronounce words like (bath, math, theatre) to pronounce them, they replace the dental $/ \theta /$ with the alveolar/s/ so they pronounce them as (bas, mas, seatre). They also have some mistakes with other fricatives ( $\mathrm{z}$ and $\varnothing$ ) they replace the dental $ð$ with the alveolar $z$, so words like (the, weather, then) are pronounce with $/ z /$ instead of /ठ/. They pronounce them as (za, weazer, zen).

The third example is their replacement of bilabials ( $b$ and $p$ ) with each other. So they usually use $/ \mathrm{b} /$ instead of $/ \mathrm{p} /$ and in very few cases $/ \mathrm{p} /$ instead of $/ \mathrm{b} /$ for instance words like (pupil, paper, apple) they pronounce them as $/ \mathrm{bju}: \mathrm{bl} /$, /beibə/, /æbl/.

It is difficult for a second language learner to speak with native-like pronunciation. Therefore this research attempts to identify the problematic areas of pronunciation and to identify the exact reasons behind them and to try to find suitable techniques that help the students to speak English with better pronunciation.

\section{Literature Review}

Many linguists and researchers on (SLA) concluded that the English pronunciation problems among speakers of other languages are the same but it is according to each language background. Arabic language is among them, so here we are going to see some of the factors that influence on learning second language (L2) in general and English pronunciation in particular and also try to identify the exact reasons behind such errors and finally try to find the suitable techniques and strategies that help the students improve their English pronunciation.

\subsection{Factors That Influence Learning English in General}

Many studies in the field of (SLA) discussed the factors that hinder achieving native-like pronunciation among foreign languages learners in general and among Sudanese learners in particular (O'Connor, 2003; Yule, 2003). Researchers and linguists have pointed some linguistic factors such as the differences of the sound system between the (LI) and the (L2), the inconsistency of some sounds in English language, the mother tongue interference and the influence of spelling on pronunciation. These factors are known as linguistic factors, which are the main topic of this research; so all of them will be discussed separately in detail as follows: 


\subsubsection{Mother Tongue Interference}

Several works have been conducted on the influence of L2 in learning English language (Catford, 1977), (Moosa, 1972) and (Swan; Smith, 2001) reported that /p/ and /b/ sounds are two different phonemes and each one is distinguished by a native speaker. In Arabic Language, the situation is different, because there is only the phoneme $/ \mathrm{b} /$ so this is the reason why most Arabic speakers mispronounce words with these sounds $/ \mathrm{p} / \mathrm{and} / \mathrm{b} /$ (of course the Sudanese students of English face the same problem. Students confuse between $/ \mathrm{p} /$ and $/ \mathrm{b} / \mathrm{e}$.g. words like ('park', 'bark'), ('pen', 'ben'), ('pull', 'bull'), ('supper', 'subber') if we ask the students to say these words, they pronounce $/ \mathrm{b} /$ instead of $/ \mathrm{p} /$ in each pair of the words above and sometimes $/ \mathrm{p} /$ is used in the place of $/ \mathrm{b} / \mathrm{but}$ this rarely happens. The reason for shifting from $/ \mathrm{p} /$ to $/ \mathrm{b} /$ is the fact that the two sounds are regarded, as they are two allophones of one phoneme.

Also in the far past, (Alkhuli, 1983) noted that Arab students of English confuse /p/ with $/ \mathrm{b} /$ and that is linked to the influence of the mother tongue, so their tongues get stiff with their LI sounds, and they commit such errors until the mastery of L2 sounds. Many other sounds are influenced by the mother tongue of foreign learners (Gruttenden, 1994) showed that foreign learners of English language should be careful not to use $/ \mathrm{t} /$ or $/ \mathrm{s} /$ for $/ \theta /$ and $/ \mathrm{d} /$ or $/ \mathrm{z} /$ for $/ \mathrm{J} / ; / / \mathrm{z} /$ and $/ \mathrm{s} /$ are used by SSE whose language background is Sudanese Spoken Arabic e.g. central and northern Sudan, and /d/ is used for / $/$ / by non-Arabic speaking Sudanese background, e.g. students who descend from southern Sudan).

In the near past (Brown, 2000) found that a second language learner meets some difficulties, because his LI affects his L2 specially in adulthood, and this effect is a result of LI transfer; so it is a significant source of making errors for second language learners. (Ladefoged, 2001; Carter \& Nunan, 2001) showed that mother tongue has clear influence on learning L2 pronunciation. Where LI and L2 rules are in conflict, errors are expected to be committed by foreign learners. All that can be linked to what is known as the interference between LI and L2. So many learners use $/ \mathrm{p} /$ as $/ \mathrm{b} /$, others use $/ \mathrm{s} /$ for $/ \theta /$ and $/ \mathrm{z} /$ for $/ \mathrm{d} /$ and $/ \mathrm{b} /$ for $/ \mathrm{v} /$.

In addition to the past works, (O'Connor, 2003; Yule, 2003) have studied pronunciation problems and the influence of LI. So many sounds such as $/ \mathrm{p} /$ and $/ \mathrm{b} /, / \mathrm{s} /$ and $/ \theta /, / \mathrm{z} /$ and $/ \mathrm{d} /, / \mathrm{t} / /$ and $/ \mathrm{S} /, / \mathrm{v} /$ and $/ \mathrm{b} /$ are confused e.g. (pit / bit), (thin / sin), (question /action), (very / berry). For the (SSEs) /z/ and $/ \mathrm{s} / \mathrm{are}$ usually used in the place of / $/$ and $/ \theta /$ which result from the interference of Sudanese spoken Arabic. $/ \delta /$ and $/ \theta /$ exist in some forms of Arabic e.g. (Iraqi, Saudi Arabian, Kuwaiti, etc); however, they do not exist in Sudanese dialect where they are replaced by /s/ and $/ \mathrm{z} /$.

The mispronunciation of the above sounds is the result of the over practice of the first language, a process of fossilization. The adults vocal musculature is set to pronounce foreign sounds with an accent (Yule; O'Connor, 2003) reported that the main problem of English pronunciation is to build a new set of sounds corresponding to the sounds of English, and to break down the arrangement of sounds which the habits and the systems of our LI have strongly built up.

And that means we use new ways of hearing and new ways of using our organs of speech. So it is too difficult to change such habits whicha learner has obtained since his childhood or at least it needs very long years to be changed and after also very long time and regular practice, and all that is linked to a certain age of the learner. So the points mentioned above altogether share the concept that the learners confuse such sounds and replace each of them with other sounds that are said to be the nearest ones to them (O'Connor, 2003).

\subsubsection{Sound System Differences between LI and L2}

As it has been mentioned by many linguists and researchers, there is a conflict between the sound systems of LI and L2 (Moosa, 1972) noted that the Arab learners of English form habits of their mother tongue (Arabic), so they strongly build the phonological features of Arabic; this makes them encounter many difficulties in distinguishing sound systems between a native language and the second language. For the SSA we discuss the problem from two perspectives, the first one is that there is a difference between the sound system in Sudanese Spoken Arabic and the sound system in other forms of Arabic language, and the second one is that there is also a difference between the sound system in Sudanese Spoken Arabic, and the sounds system inEnglish language.

Another study on the effect of sound system on learning pronunciation was done by (Alkhuli, 1983) who showed that the main problem in teaching and learning English pronunciation result from the differences in the sound system of English and the native language, so a speaker of Sudanese Spoken Arabic is not accustomed to pronounce for instance $\theta$-sound and $\circlearrowright$-sound, because they do not found in his native language. This means that the organs of speech of the learner are not trained to produce such sound systems because they are unfamiliar to him; that is why he uses the nearest sounds such as $/ \mathrm{s} /$ and $/ \mathrm{z} /$. About the same area of the study (Cruttenden, 1994) 
noted that in the field of (SLA), learners with different linguistic backgrounds would of course face different difficulties in order to produce English sounds, because of the differences between the two languages (e.g. English and Arabic).These differences between the sound systems are regarded as a barrier against competence in the pronunciation of English, because the new sounds still remain strange for their organs of speech specially if they start learning English after the age of adulthood, but this problem is expected to be solved after a long time of regular practice and hard work.

Most of the Sudanese Students of English face such problem because in Arabic the vowel system is very simple and the learner can read an Arabic word easily without any confusion, but in English he may pronounce /i/ for /e/ for example /sit/, /set/. Also about sound system differences between LI and L2. In English the /r/ is distinctly pronounced only before a vowel e.g. the $/ \mathrm{r} /$ after a vowel is not pronounced. In Arabic however, the $/ \mathrm{r} /$-sound is distinctly pronounced in all positions, before or after a vowel. So the Sudanese students of English pronounce $/ \mathrm{r} /$ in any position of an English word for instance in words like red, room, and river.

In Arabic, each letter represents only one sound, so it's easy to read any word from a written text. Also there is no sound which is not pronounced (silent), as it happens a lot in English. When there is a difference in the sound system in the LI and L2 showed that errors are expected to be committed because the learners transfer their mother tongue sound system into the target language (Nunan, 2001).

The (SSEs) as speakers of Arabic tend to replace /v/ by /f/ or /b/ because this sound does not exist in their native language sound system. So their speech organs are not trained to produce such sound. They pronounce very as berry or ferry and van as fan. The learners difficulties hi a L2 could be predicted based on systematic differences of the two languages, and those learners from different first language backgrounds would experience different difficulties when attempting to learn a L2. It was also reported that it is essential to understand which sounds in a language are phonemes because they express the differences in meaning and the learner should be able to pronounce them, otherwise he commits errors.

In English language there are twenty-four consonants and twenty vowels; that mean there are forty-four phonemes in English language the learner should be able to produce them while he is learning English. Learners of different language backgrounds will of course face some difficulties to pronounce them because of their language background (O'Connor, 2003).

In Arabic language the whole number of the sounds is less than the one in English language, so the total sounds of Arabic language are twenty-eight letters each of them represents only one sound. So there are only twenty-eight sounds in Arabic language. As we know a sound is made by definite movement of the organs of speech, so to produce any sound that means to perform the exact organs movement of the sound. If the learner's language sound system has not any of the forty-four English sounds, he will face a difficulty to produce it e.g. ( $\partial, \theta, p, v)$ sounds which do not exist in Sudanese Spoken Arabic sound system, so Sudanese students pronounce them incorrectly and the reason for that is the differences between the sound system in the LI and L2.

\subsubsection{Inconsistency of English Vowels}

One of the important problems faced by the students of English in general and the Sudanese students of English in particular, is that each English vowel sound has more than just one pronunciation. So this causes many difficulties to the learners and leads them to a mispronunciation (Cruttenden, 1994) noted that the main difficulty for all those whose own languages have a less complex vowel system, lies in the establishment of the qualitative oppositions. Instead of using the exact quality and quantity of a special sound, the learner erroneously changes either the quality or the quantity of the sound; so in a certain word the learner tends to use the variant sounds e.g. in words like son/s $\Lambda \mathrm{n} /$, come $/ \mathrm{k} \Lambda \mathrm{m} /$, among /əm $\Lambda \mathrm{y} /$, monkey $/ \mathrm{m} \Lambda \mathrm{nki} /$, blood $/ \mathrm{bl} \Lambda \mathrm{d} /$, flood /fl $\Lambda \mathrm{d} /$; in all these words $/ \mathrm{o} /$ and /oo/ stand for the same sound of $/ \Lambda /$, but most of the learners, unless they have a mastery of the pronunciation of such vowels, they pronounce $/ \mathrm{J} / \mathrm{or} / \mathrm{u}: /$ in the place of $/ \Lambda /$. This is because of their first background about each sound, so they picture this thought in their minds as if each vowel has only one type of pronunciation and if that is true the learner can easily know and expect how to pronounce each word even if he is seeing it for the first time. That is if each letter represents only one phoneme, but in fact the situation is not like this, and that is one of the basic problems of English.

(O'Connor, 2003) reported that it is not simple to know the exact sounds the letters stand for or represent in a certain word for instance in the words city /siti/, busy /bizi/, women/wimin/, pretty/priti/, village/vilid3/, English /i $\mathrm{y} \mathrm{glif/}$ the letters $\mathrm{y}, \mathrm{u}, \mathrm{o}, \mathrm{a}, \mathrm{e}$, all of them stands for the same vowel sound $/ \mathrm{i} /$. In words like, banana /bəna:nə/bather /beiðə/(r)/, man /mæn/, many /meni/ the 'a' stands for five different vowels sound. The learner, who doesn't have sufficient knowledge of different pronunciations of the vowels above, meets some difficulty, since he uses different variants of their pronunciations. Power (2003) found that there are 23 common 
pronunciation problems, some of them are related to vowels e.g. the students confuse /i/ with /i:/ as in sit, seat, and /o/ with /ou/ as in not,note and / æ/ with /ei/ as in mat, mate and /e/ with /ei/ as in let, late.

Researchers and linguists always connect such problems with the complexity of the vowels sound system that exists in English and the inconsistency of its pronunciation. (Cruttenden, 1994) noted that the inconsistency of English vowels causes difficulties for other language learners of English e.g. if we take for instance ' $\mathrm{o}$ ' in some words like some, move, home, women, in each word it has different pronunciation as $/ \mathrm{N} /, / \mathrm{u}: /, / \mathrm{ou} /, / \mathrm{i} /$ so the English learners who don't have the mastery of the pronunciation of such words will also face difficulties. On the other hand words such as book, butcher, could, wolf etc in all these words the letters oo, $\mathrm{u}, \mathrm{ou}, \mathrm{o}$ are all pronounced the same /u:/, so in the first example we have same letters with different pronunciation, and in the other one we have different letters with same pronunciation. For more examples of the different pronunciations of the letter a consider water, same, fat, the letter (a) has three different pronunciations, as / $/ \mathrm{A} /, / \mathrm{ei} /, / \mathfrak{a} /$ so many of the Sudanese students of English tend to pronounce /ei/ instead of /æ/e.g./feit/ for /fæt/. Also in words such as rich, symbol, English, private, women the letters i, y, e, a, o all of them are pronounced as /i/ so we have /rit $/$, /simbl/, /injli $/$, /praivit/, /wimin/. In such words, errors are expected to be committed by the Sudanese students of English unless they are already taught and trained in their different pronunciations. Each of the letters we use to show

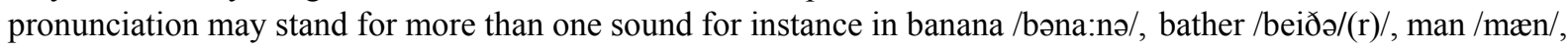
many /meni/, the letter (a) stands for five different vowel sounds; if the learner has no knowledge about this inconsistency, this will lead him to wrong pronunciation (O'Connor, 2003).

\subsubsection{Influence of Spelling on Pronunciation}

According to the observations and notes on the Sudanese students at Sudan University of Science and Technology (SUST) it was found that, the (SSEs) have some difficulty in the pronunciation of some words from a written text. This problem is due to the spelling system in English language, because in Arabic language students can easily pronounce a word from a written text just by looking at it; so each letter represents one sound, so the relationship between the orthography and the phonology is very easy to distinguish, in addition to that there is no silent letter in Arabic language as it is found in English. Many words in English have letters, which are not pronounced. (Yule, 2001) noted that the sounds of spoken English do not match up, a lot of time, with letters of written English. So if we cannot use the letters of the alphabet in a consistent way to represent the sounds we make, it is difficult to describe the sounds of a language like English. In English, there are twenty-four consonants and twenty vowels; if we give to each of these forty- four units a special letter, in that way undoubtedly we can show what the student should say. If the learner knows that each letter represents a certain sound (e.g. equal number of sounds to the letters), he can simply avoid the difficulty of spelling on pronunciation.

Some words which are ordinarily spelt in the same way, are different in their pronunciation, for example lead which is pronounced /Ii:d/ in a phrase like, lead the way, but /led/ in another phrase lead pipe. Also there are some words spelt differently, but sound the same e.g. rain, rein, reign, all of them are pronounced /rein/. The learner who still doesn't have the mastery of pronunciation of such words, pronounces each of them by looking at its spelling, and he is expected to mispronounce them (O'Connor, 2003).

The explanatory potential of sound-spelling relationships (Carter; Nunan, 2001) reported; is something teachers should be aware of, since correspondences between orthography and phonology enables the students to predict the pronunciation of words from their spelling. So if the learner doesn't know such relationship between sound and spelling, he mispronounce words by just looking at their spellings e.g. before the $\mathrm{n}$ the $\mathrm{k}$ is silent; knee, know, knot, knight a student who didn't learn their pronunciation correctly, pronounces them with the $/ \mathrm{k} /$ sound. Also (Easton, 2005) showed that there are some words with silent letters which cause problems for the learners for instance, silent $/ \mathrm{g} /$ and pronounced /g/ e.g. campaign, reign, sign, gnash in these words the /g/ is silent, but most of the students pronounce it. On the other hand, words like signal, signature, resignation the /g/ here is pronounced; unless the learner has a good knowledge of pronunciation of $/ \mathrm{g} /$ in such words, he will confuse its pronunciation. In the same problem of pronunciation as a result of spelling (Easton, 2005) noted that in silent /gh/ the learners may face problem because written $/ \mathrm{gh} /$ has no sound of its own, so it is never pronounced as it is written e.g. $/ \mathrm{gh} /$, but it is pronounced as /g/ in some words as, Afghanistan, Ghana, ghost, and in other words pronounced as If/ e.g. cough, trough, enough and silent in some other words such as light, night, high, weigh, weight, thorough, bough, plough. Any time the student meets such words he will be confused to pronounce them correctly he just guesses the pronunciation by looking at the spelling of the word unless he has previous background. So it is very important to consult the dictionary from time to time to check the pronunciation of such words until he possesses a good mastery of their pronunciation. 
One of the problems other languages learners of English face is the (r) which is very week in its pronunciation in English (Cruttenden, 1994; Ladefoged, 2001) noted that in most forms of British English (r) can occur only before a vowel e.g. in words like red, ruler, ride, but the foreign learner should notice that its very weak and it is not pronounced like the Arabic one. All the above notes show that in many cases the spelling of English words lead the learners to guess the wrong pronunciation from the spelling of the words unless they have a good knowledge of English sounds and letters relationships and the way they are pronounced. Also (Cruttenden, 1994) reported that RP (r) occurs only before a vowel and the air stream is allowed to escape freely, without friction, over the center part of the tongue, that means it is not pronounced strongly as many Arab and (SSEs) do, so they pronounce (r) as they pronounce it in their language because they think each letter in a word should be pronounced as it happens in their native language; so words like car /ka:(r)/, arm /a:m/, horse /ho:s/, hurt /h3:t/ if we ask the learners to pronounce them they just look at the spelling of each word and try to pronounce it e.g. /ka:r/, /a:rm/, /hว:rs/, /h3:rt/, so learners should not be misled by the spelling in the pronunciation of such words.

\section{Method}

In this study, the data has been collected from 50 students (first year) of SUST, College of Education after they have completed a whole year at the university. Samples of their pronunciation were recorded in addition to the observation in which some notes were written about their pronunciation. A structured questionnaire to be answered by the university teachers to write their opinions and ideas about the exact reasons that make SSEs mispronounce some English sounds, and suitable ways that help them improve their pronunciation. All the data were analyzed later on statistical and descriptive basis.For calculating the validity and the reliability of the questionnaire different methods were used e.g. Split-half using Spearman-Brown equation. For the reliability and the validity of the findings of the whole study sample some statistical instruments were used such as mean, median and Chi-square Test, and this is described in detail in the discussion section of the whole study.

\subsection{Population and Sample of the Study}

The original population of this study was all the students of English at all the Sudanese universities and schools . The sample of the study contained two parts; the first part was (50) of the students who were chosen from Sudan University of Science and Technology SUST. The (50) students were" chosen to do the recording for the study test. The second part of the sample was (30) of the teachers of English at SUST. The teachers responded to questionnaire on the exact sounds which the students mispronounce and the reasons for pronunciation problems facing the students at SUST.

The researcher followed the descriptive and statistic method in this study. And as we know the descriptive researches attempt to describe the problems and the phenomenon as it is i.e. describes the phenomenon and explains it. Then offer the recommendations for solving the problem. Also the analytical method was used in this study, to test the hypotheses of the study by using suitable statistical procedures.

\subsection{Tools of Data Collection}

It is known that the tool of any study is the instrument which any researcher uses for collecting the required data for the study. There are many types of tools used in the field of scientific research. In this research, the researcher depended on tape recordings and observation to collect the data from the sample of the students. On the other hand, a structured questionnaire was used to collect the information from the sample of the teachers. The questionnaire contained (22) items reflects the opinions and ideas of the teachers about the pronunciation of some SSE. In the questionnaire each teacher was asked to choose one answer according to the Tri Regression Measurement, which contains three levels (agree-not sure-disagree).

\subsubsection{Observation}

Observation was the first tool, which was used in this research.

To obtain information about errors, the researcher engaged in direct conversations with the students inside the classroom during their university day. A number of topics, which are of particular interest to the students, were discussed: The students first day at the university, unforgettable story and Sudanese traditions and customs. While the students were doing this, the researcher was taking notes about some particular sounds he expected that the students cannot pronounce correctly, or which the students may replace with other sounds which may be close to them in the place of production.

The hypotheses was that the Sudanese students pronounce /b/ instead of /p/, /s/ instead of / $/$ /, /z/ instead of / $/$ /, /f/ instead of $/ \mathrm{v} /$. Most of the students were very interested and they were very happy to express themselves in English; while they were doing that, the researcher was writing notes carefully about their errors. At the end of the process of the observation it was found that many of the SSEs face such problems for instance most of them pronounce/b/ 
instead of /p/ for example in words such as "pen", "happy", also they pronounce /s/ instead of / $\theta$ / in words such as "thank", "both" etc. Some notes were written about the SSE pronunciation of some English vowels for instance they pronounce /ai/ instead of /i/ in words such as "infinite", "service", and some of them pronounce/ei/ instead of $/ \mathrm{s} /$ in words such as "also" and "fall". Errors of pronunciation in the same sounds were tested using audio recordings of a chosen number of sentences. It is noteworthy that tape recording permits the repetition when needed. To verify the pronunciation of the problematic sounds among the students, teachers were asked to fill a questionnaire regarding the pronunciation of their students.

\subsubsection{Recording Test}

Samples of pronunciations can be repeated as many times as you need and this will enable you to identify the errors Many of the researchers in the previous studies have depended on recordings as a tool of collecting their data e.g. (Ma; Lin, 1994) used audio recordings to investigate to what extent adult native speakers of Mandarin Chinese learning English as a second language could pronounce five front vowels of English and how difficult this was, and which vowels were most difficult. Recordings were used by (Atwel, 2001) in his project ISLE (Interactive Spoken Language Education). The ISLE project collected a sample of audio recordings of German and Italian learners of English reading aloud selected samples of English text and dialogue to train the speech recognition and to correct pronunciation errors.

(Wei; Zhou, 2002) applied audio recordings to investigate problems with English pronunciation among Thai students. In this study for testing the pronunciation errors among the SSEs, the researcher prepared (10) sentences written on a paper in each sentence there was a target sound e.g. /ə/ in the word "obstacle", also in a sentence such as "service not advice" the target sound is the vowel /i/ in "service".

As it was mentioned before the sample of this study was (50) of the SSE at SUST; all of them speak Sudanese Spoken Arabic and they have studied the same English course during their school stage. The test took place after they have completed their first year at the university. Each of the students read the whole ten sentences aloud while the researcher was recording their pronunciations. The whole process took about two hours to complete .Sounds such as $/ \theta /, / \mathrm{d} /, / \mathrm{p} /, / \mathrm{t} \mathrm{J} /$ were included in the sentences to be pronounced by the SSEs as target sounds in order to confirm or reject that the SSEs have problems in these sounds and to identity the exact consonants that SSEs do not pronounce correctly or which may replace them with others.

After each of the (50) SSEs recorded his sound reading the ten sentences loudly inside the classroom, the researcher later listened carefully and many times to samples of the SSEs recorded pronunciations and repeated this process a lot of times playing the tape at home.A list of the recorded sounds was later written. The researcher wrote down the number of students with the correct pronunciation and the number of the students with incorrect pronunciation was recorded. Then the figures were analyzed descriptively; percentages were computed.

It is worthy of mention that the errors which were found and written from the audio recording test were very similar to the errors which the researcher wrote on his notes during the observation to the SSE pronunciation. This consolidated results of the observation.

The statistics used in this study, for the recorded test, is very simple and clear. Percentages from the data collected were computed. Samples of the pronunciations were recorded on the tape; then these recorded sounds were counted to see the total number of the correct answers done by the whole (50) subjects in all items of the test, then the total number of the incorrect answers was also calculated. The percentage was worked as follows; for instance in the test of/p/ sound the whole number of students who pronounced the sound were (50), the number of the students with correct pronunciation was (14), and the number of the students with incorrect pronunciation was (36). So to calculate the percentage of the students with the correct pronunciation in $/ \mathrm{p} / \mathrm{sound}$ the following process was followed:

$$
\text { No. of students with correct pronunciation }=\frac{14}{50} \times 100=28 \%
$$

The above calculation indicates that only $28 \%$ among the whole number of the learners are able to pronounce the $/ \mathrm{p} /$ sound correctly. On the other hand, to calculate the percentage of the students with incorrect pronunciation the following process was followed:

$$
\text { Students with incorrect pronunciation }=\frac{36}{50} \times 100=72 \%
$$

The above statistics show that $72 \%$ of the students among the whole group are not able to pronounce /p/ sound correctly. 
In general, the whole data and the information collected were analyzed descriptively and statistically. For the recording test, allthe sounds recorded from the students were written down on papers, using tables to put each sample of pronunciation beside the student who pronounced it and the number of correct and incorrect pronunciation was counted beside each student. The recording test supported a lot the notes and the information, which was taken from the observation.

\subsubsection{Questionnaire}

The third tool used in this study was a structured questionnaire, which was prepared in collaboration with some English teachers at SUST and checked by one of the university professors. For the faith validity, the questionnaire was designed to collect the data that support the study and to confirm findings from the preceding tools used in collecting the data. For the validity of the questionnaire before distributing it to the whole members of the sample, a number of ten questionnaires were given to (10) teachers of English as pilot group; If all of them answered the questions easily. After that these (10) questionnaires were taken as a sample and analyzed statistically to make the reliability and the validity coefficient so each questionnaire comprised (22) items; these twenty-two items were divided into two equal parts; the first part contained (11) items which numbered $(1,3,5,7,9,11,13,15,17,19,21)$ (odd numbers), the second part contained the items which are numbered $(2,4,6,8,10,12,14,16,18,20,22)$ (even numbers). When the correlation coefficient between the two parts was counted statistically, the result was (0.47). To calculate the reliability coefficient; the researcher followed the Spearman Brown Equation and the value of the reliability coefficient was $(64 \%)$, and the validity coefficient value was $(80 \%)$. These two values show that the questionnaire was valid and reliable.

After that a number of (30) copies of the questionnaire were printed and answered by (30) university teachers from SUST within a week time. The questionnaire consisted of (22) items asking about the exact consonants that SSEs mispronounce e.g. do they replace $/ \theta /$ with $/ \mathrm{s} /, / \mathrm{p} /$ with $/ \mathrm{b} /, / \delta /$ with $/ \mathrm{z} /$. Also the questionnaire contained questions about some vowels that SSEs mispronounce like the same vowels they mispronounced when the recording test was conducted on them. So the teachers have to support whether SSEs pronounce /ai/ instead of $/ \mathrm{i} /$ in words such as "service", "infinite" etc, or whether they replace/a/ with /ei/ in words such as "obstacle". Also the questionnaire contained questions asked the teachers to say their opinions about influence of MTI on pronunciation and the reasons that make the SSE commit such pronunciation errors e.g. do they mispronounce consonants such as $/ \mathrm{v} /, / \theta /$, $/ \delta /, / \mathrm{p} /, / \mathrm{t} \mathrm{S} /$ because they don't exist in SSA. Also teachers explained their ideas in the questionnaire about the influence of the inconsistency of some English vowels and consonants; also weather the sound system differences between Arabic and English have a role in such problems of pronunciation. And finally the last part of the questionnaire asked the respondents to say their opinions about the recommending solutions for such errors e.g. weather looking up words in the dictionary and listening to the English sounds and words in the audio aids help SSE improve their English pronunciation. The statistical treatments used for the questionnaire were the median, standard deviation and Chi-square test was also used to confirm the figures. The result was very acceptable, and all the statistical procedures were done by a specialist university scholar using a computer and the Statistical Package for Social Sciences (SPSS). All that helped a lot to obtain very accurate results and findings and to make sure of the validity and reliability of the questionnaire. After that, the results and the findings of the questionnaire were analyzed descriptively and statistically of the questionnaire also did the reliability and the validity and all the statistical treatments. The results and the information of the questionnaire and the recordings will be reviewed with a short comment in the next chapter and discussed in farther details in the last chapter at the end of the study.

\section{Results and Discussion}

\subsection{The Recorded Test}

The aim of this test is to identify the pronunciation errors among the Sudanese students of English when they are speaking or reading English. So a number of words were chosen randomly, but each word contains a sound, which is expected to be pronounced incorrectly by the Sudanese students of English language. The test contains some vowel sounds and consonant sounds. The words were put in sentences; each sentence contains one target sound: each student was asked to read all the sentences aloud, while his voice was recorded. At the end of this process, the errors were written on a paper and then tabulated and analyzed statistically and descriptively. 
Table 1. The pronunciation of some English vowels by the SSEs

\begin{tabular}{lllllll}
\hline Word & TS & NS & NSC & $\%$ & NSI & $\%$ \\
\hline Obstacle & $/ \mathrm{a} /$ & 50 & 9 & 18 & 41 & 82 \\
Service & $/ \mathrm{i} /$ & 50 & 17 & 34 & 33 & 56 \\
Pronunciation & $/ \mathrm{a} /$ & 50 & 13 & 26 & 37 & 74 \\
Tutor & $/ \mathrm{ju} / /$ & 50 & 4 & 8 & 46 & 92 \\
Engagement & $/ \mathrm{i} /$ & 50 & 47 & 94 & 3 & 6 \\
\hline
\end{tabular}

Note. $\mathrm{TS}=$ target sound; $\mathrm{NS}=$ number of students; $\mathrm{NSC}=$ number of students with correct pronunciation; $\mathrm{NSI}=$ number of students with incorrect pronunciation.

As seen from the table, only (9) (18\%) of the SSE were able to give the correct pronunciation of the target sound in the word obstacle. With the word service, we notice that only (17) (34\%) of the f SSE among the-sample (50 students) were able to pronounce the /i/ sound correctly. In the word pronunciation the target sound / a /was only pronounced correctly by 13 students among the whole 50 students of the sample. The same is true for the word tutor, because only 4 students were able to pronounce the sound correctly. For the word engagement, the target sound was $/ \mathrm{i} / ; 47$ students pronounced the sound correctly.

According to the results above, it could then be said that the most of the SSEs do not have mastery on different pronunciations of vowels. The results of the recorded test in table 1 show that (46) (92\%) of the subjects failed to pronounce the target sound /ju:/ correctly in the word tutor so most of the students tend to pronounce it as / $\mathrm{J}$. The results of the questionnaire go in the same way with the results of the recorded test, so (18) of the teachers out of 30 believe that some SSEs pronounce / $/$ / instead of /ju:/ in the word tutor.

Table 2. The pronunciation of some English consonants by the SSEs

\begin{tabular}{|c|c|c|c|c|c|c|}
\hline Word & TS & NS & NSC & $\%$ & NSI & $\%$ \\
\hline have & $/ \mathrm{v} /$ & 50 & 13 & 26 & 37 & 74 \\
\hline experience & $/ \mathrm{p} /$ & 50 & 14 & 28 & 36 & 72 \\
\hline thank & $/ \theta /$ & 50 & 0 & 0 & 50 & 100 \\
\hline much & $/ \mathrm{t} /$ & 50 & 4 & 8 & 46 & 92 \\
\hline weather & $/ \partial /$ & 50 & 6 & 12 & 44 & 88 \\
\hline
\end{tabular}

As seen from the table above, only (13) (26\%) of the SSE were able to pronounce the target sound / $/$ / correctly in the word have. In the second word, experience the target sound was $/ \mathrm{p} /$; and it is noticed that only 14 of the SSE among the whole sample (50 students) were able to pronounce the sound correctly. Also in the word thank none of the students pronounced the target sound $/ \theta /$ correctly. Also in the word much, 46 of the students failed to pronounce $/ \mathrm{t} /$ / correctly. Also in weather, only 6 of the SSE among the whole sample were able to pronounce the target sound / $/$ correctly. According to the results above, it could then be said that, most of the SSE mispronounce the English consonants that do not exist in Arabic language and other consonants, which are inconsistent.

\subsection{The Questionnaire}

After collecting the data from the respondents (30 teachers), the results were tabulated and the string variables (agree, not sure, disagree) were changed into quantity variables $(1,2,3)$ orderly, then the answers were tabulated in the following table:

Table 3. The median of respondents answers about the items of the main hypothesis

\begin{tabular}{|c|c|c|c|}
\hline No. & item & median & Result \\
\hline 1 & $\begin{array}{l}\text { Do you think Sudanese students of English (SSE) pronounce /f/ instead of } \\
\text { /v/ in words like "have", "van", "marvel". }\end{array}$ & 3 & Agree \\
\hline 2 & $\begin{array}{l}\text { Most of the SSE pronounce /b/ instead of /p/ in words like"pen", "map", } \\
\text { "happy". }\end{array}$ & 3 & Agree \\
\hline 3 & $\begin{array}{l}\text { Some of the SSE pronounce /s/ instead of } / \theta / \text { in words like "think", "math", } \\
\text { "mathematics". }\end{array}$ & 3 & Agree \\
\hline 4 & $\begin{array}{l}\text { Many SSE pronounce } / \int / \text { instead of } / \mathrm{t} \int / \text { in words such as "much", } \\
\text { "furniture". }\end{array}$ & 3 & Agree \\
\hline 6 & Some SSE pronounce /z/ instead of /d/ in words like "then", "weather". & 3 & Agree \\
\hline
\end{tabular}


- The calculated value of the median for the teachers' answers of the first item is (3). This value means that, most of the teachers think that some SSEs pronounces /f/ instead of $/ \mathrm{v} /$ in some words such as marvel, have, and van.

- The calculated value of the median for the teachers' answers of the second item is (3). This value means that, most of the teachers agree that some SSEs pronounce /b/ instead of $/ \mathrm{p} /$ in some words like happy, map, and pen.

- The calculated value of the median for the teachers' answers of the third item is (3). This value means that, most of the teachers agree that some SSE pronounce mathematics math, think /s/ instead of/ $\theta$ / in some words such as:

- The median for the teachers' answers of the fourth item is (3). This value means that, most of the teachers agree that some SSEs pronounce / $\int /$ instead of $/ \mathrm{t} /$ / in some words such as, much, furniture

- The calculated value of the median for the teachers' answers of the sixth item is (3). This value means that, most of the teachers agree that some SSEs pronounce /z/ instead of/ $\partial /$ in some words such as, weather, then.

The above results do not mean that all the teachers in the sample agree with the items in the study.

There are some teachers who are not sure and others who do not agree (see the appendix). So to test statistical significance of the differences between the answers of the teachers for the main hypothesis, the Chi-square Test was used to indicate the differences for each item of the hypothesis. Table 4 explains the results of the test for the items as follows:

Table 4. Chi-square tests results for respondents' answers about the items of the main hypothesis

\begin{tabular}{|c|c|c|c|c|}
\hline No & Item & $\begin{array}{l}\text { Chi-square value } \\
\text { (calculated) }\end{array}$ & d.f & $\begin{array}{l}\text { Chi-square value } \\
\text { (tabulated) }\end{array}$ \\
\hline 1 & $\begin{array}{l}\text { Do you think Sudanese students of English (SSE) pronounce /f/ } \\
\text { instead of /v/ in words like "have", "van", "marvel". }\end{array}$ & $19.40 * *$ & 2 & 9.21 \\
\hline 2 & $\begin{array}{l}\text { Most of the SSE pronounce /b/ instead of /p/ in words like"pen", } \\
\text { "map", "happy". }\end{array}$ & $22.53 * *$ & 1 & 6.63 \\
\hline 3 & $\begin{array}{l}\text { Some of the SSE pronounce } / \mathrm{s} / \text { instead of } / \theta / \text { in words like } \\
\text { "think", "math", "mathematics". }\end{array}$ & $38.60 * *$ & 2 & 9.21 \\
\hline 4 & $\begin{array}{l}\text { Many SSE pronounce } / \mathrm{S} / \text { instead of } / \mathrm{t} \int / \text { in words such as } \\
\text { "much", "furniture". }\end{array}$ & $14.60^{* *}$ & 2 & 9.21 \\
\hline 6 & $\begin{array}{l}\text { Some SSE pronounce /z/ instead of /ठ/ in words like "then", } \\
\text { "weather". }\end{array}$ & $34.20 * *$ & 2 & 9.21 \\
\hline
\end{tabular}

Note. $(* *)=$ there are statistical differences at $(1 \%)$ level, $\mathrm{n} . \mathrm{s}=$ there are no statistical differences, $\mathrm{df}=\mathrm{degree}$ of freedom

According to the table, we can demonstrate the results as follows:

- The calculated value of Chi-square for the significance of the differences for the teachers answers in the 1st item was (19.40) which is greater than the tabulated value of Chi-square at the degree of freedom (2) and the significant value level (1\%) which was $(9.21)$. According to table 4 this indicates that, there are statistically significant differences at the level (1\%) between the answers of the teachers, which support the teachers who believe the SSE pronounce $/ \mathrm{f} /$ instead of $/ \mathrm{v} /$ in some words such as van, have, marvel.

- The calculated value of Chi-square for the significance of the differences for the teachers answers in the 2nd item was (22.53) which is greater than the tabulated value of Chi-square at the degree of freedom (1) and the significant value level (1\%) which was (6.63). According to table 4, there are statistically significant differences at the level $(1 \%)$ between the answers of the teachers, that support the teachers who agree the SSE pronounce $/ \mathrm{b} /$ instead of $/ \mathrm{p} /$ in some words such as 'happy', 'pen', 'map'.

- The calculated value of Chi-square for the significance of the differences for the teachers answers in the $3 \mathrm{rd}$ item was (38.60) which is greater than the tabulated value of Chi-square at the degree of freedom (2) and the significant value level (1\%) which was $(9.21)$. According to table 4 , there are statistically significant differences at the level (1\%) between the answers of the teachers, which support the teachers who believe the SSE pronounce $/ \mathrm{s} /$ instead of $/ \theta /$ in some words such as 'think', 'math', 'mathematics'.

- The calculated value of Chi-square for the significance of the differences for the teachers' answers in the 4th item was (14.60) which is greater than the tabulated value of Chi-square at the degree of freedom (2) and the significant value level (1\%) which was (9.21). According to table 4, there are statistically significant differences at the level (1\%) between the answers of the teachers which support the teachers who believe the SSE pronounce $/ \mathrm{J} /$ instead of $/ \mathrm{t} \int /$ in some words such as 'much', 'furniture'. 
- The calculated value of Chi-square for the significance of the differences for the teachers answers in the 6th item was (34.20) which is greater than the tabulated value of Chi-square at the degree of freedom (2) and the significant value level (1\%) which was (9.21). Table 4 indicates that, there are statistically significant differences at the level (1\%) between the answers of the teachers, that support the teachers who believe the SSEs pronounce $/ \mathrm{z} / \mathrm{instead}$ of $/ \delta /$ in some words such as weather, then.

According to the results above we can say that, the main hypothesis (some SSEs mispronounce these sounds) (/t $\mathrm{f} /$, $/ \mathrm{J} /, / \theta /, / \mathrm{p} /, / \mathrm{v} /)$, is fulfilled.

\section{Conclusion and Recommendations}

\subsection{Conclusion}

This study was initiated by the observation of some students who mispronounce some English words e.g. /b/ and $/ \mathrm{p} /, / \mathrm{s} /$ and $/ \theta /, / \mathrm{z} /$ and $/ \delta /$.

Although some scholars e.g. (Ted Power, 2007) argued that such problems it may not sometimes lead to a misunderstanding because, he continued to say: "if someone said to me: tomorrow I am going to London to visit Pig Pen I would know from the context he meant Big Ben". He further argued that Arabic consonants are more than English ones, so Arab students are expected to be quite good in English consonants. The researcher however believes that such problems still considered as big ones for a person who wants to speak with correct or intelligible pronunciation, and for someone whose career in the future is related to the field of English language.

It was noticed that many SSEs have problems with the pronunciation of monophthongs that have more than one way of pronunciation; Ted power considers the mispronunciation of vowels are of minor importance if compared with the long vowels, diphthongs, stress and intonation .However the researcher believes that it is a serious error to mispronounce /servis/ as /servais/ or/meik/as /mæk/.

Confusing $/ \mathrm{s} /$ and $/ \theta /, / \mathrm{z} /$ and $/ \mathrm{J} /, / \mathrm{p} /$ and $/ \mathrm{b} /, / \mathrm{v} /$ and $/ \mathrm{f} /, / \int /$ and $/ \mathrm{t} \int /$ usually lead some SSEs to a mispronunciation and they may lead the listener to a misunderstanding.

The mispronunciation of the SSEs is due to lack of the problematic phonemes in Arabic. The phoneme contrasts affect many common English words, so poor production of these sounds will be very noticeable.

Based on the results of this study it can be concluded that manySSEs have problems in the pronunciation of the voiceless bilabial $/ \mathrm{p} /$ and the voiced bilabial $/ \mathrm{b} /$. According to the results, many SSEs substitute $/ \mathrm{p} / \mathrm{with} / \mathrm{b} /$ in words such as 'pen' 'map', 'happy' and rarely replace /b/ with $/ \mathrm{p} /$.

Other consonant sound contrasts which SSEs mispronounce are the dental fricative $/ \theta /$ and the alveolar fricative $/ \mathrm{s} /$, so in words such as 'think', 'math', 'mathematics' the SSEs replace $/ \theta /$ with $/ \mathrm{s} /$.

SSEs also have problem with the voiced dental fricatives $/ d /$ and $/ z /$, so many of the SSEs pronounce $/ \theta /$ in the place of $/ \mathrm{z} /$ for instance in words like 'then', 'weather' more consonant contrast sounds like /f/ and $/ \mathrm{v} /, / \mathrm{f} /$ and $/ \mathrm{t} / \mathrm{f}$ are mispronounced by most of the SSEs, e.g., in words like 'van', 'seven', 'have', they pronounce $/ \mathrm{f} /$ instead of $/ \mathrm{v} /$. Also the substitution of $/ \mathrm{J} /$ and $/ \mathrm{t} \int /$ is noticeable in the pronunciations of many SSEs in words such as 'much', 'furniture', 'teacher'. Other cases of mispronunciation of English sounds by the SSEs are the soft ' $\mathrm{C}$ ' $/ \mathrm{s} /$ and hard ' $\mathrm{C}$ ' $/ \mathrm{k} /$. In some words like 'concern' some SSEs pronounce /k/ instead of / s /. Also soft 'g'/dz/ and hard ' g' /g/ are problematic for the students, so they sometimes pronounce /g/ instead of / d $3 /$ as in' engagement'. Pronunciation problems such as the ones mentioned above are linked to factors such as interference of the mother tongue on the second language, also differences in the sound systems between Arabic (generally) and Sudanese Spoken Arabic (particularly) are behind many pronunciation errors. Also the spelling of some English words leads many SSEs to wrongly guess the pronunciation just by looking at the word and its letters and produce incorrect pronunciation. Finally, the inconsistency of some English consonants makes the students unable to decide what the exact sound they should pronounce is, in addition to that there are some sounds represent a combination of more than one letter e.g. 'gh' which is sometimes pronounced /f/ and other times pronounced $/ \mathrm{J} /$ and ' ch' which is pronounced $/ \mathrm{k} /$ and $/ \mathrm{t} \int /$ or $/ \int /$. The notes mentioned are considered to be the most recognized reasons for such pronunciation problems. On the other hand, many SSEs mispronounce vowels because each English vowel has more than one way of pronunciation. Many SSEs confuse the different pronunciations of each of the vowels (a, e, i, o, u). In a word like 'obstacle' many students pronounce /ei/ or /i/ or /æ/ instead of / / /. Also the pronunciation error by the SSEs is noticeable in a word such as 'women', so they fail to pronounce the target sound of the two vowels /i/. Also in words such as 'service', 'city', 'promise' the students tend to pronounce the short vowel /i/ as the diphthong /ai/ as it is pronounced in 'invite'. So many students fail to identify the exact pronunciation of a particular vowel, which has more than one pronunciation in a particular word. If we take the words such as 'put', 'cut', 'tutor', we find that there is three different pronunciations for the same vowel which is /put/, /kıt/,/tju:tə (r)/ 
so these different ways of pronunciation of this vowel causes difficulty to many SSEs, The same problem is faced by the SSEs in the pronunciation of the vowel sound in the words 'come', 'women', 'home' which is $/ \mathrm{k} \wedge \mathrm{m} /$, /wimin/, /h o u m/also we have three different Pronunciations for the same vowel. On the other hand there are some English words which are spelt differently, but pronounced the same e.g. hi 'city', 'private' 'English', 'women', 'busy' we have five different vowels (y, a, e, o, u) all of them are pronounced the same as /i/. This inconsistency in the English sounds leads many SSEs to a mispronunciation. If each English vowel or consonant has just one way of pronunciation, then the student will be able to produce the precise pronunciation. Finally, we can conclude that such pronunciation errors are related to factors such as the inconsistency of many English sounds on the one hand: on the other hand the sound system differences, which have phonological basis (depend on variation in speech organ positions or breath control.

\subsection{Recommendations}

According to the results of the study, we can recommend the following:

- Teaching should focus on both recognition and production i.e. teachers should recognize the pronunciation errors and correct them and teach the students how to pronounce these sounds correctly.

- The study suggests that there should be pronunciation lessons ranking the same as lessons in other skills e.g. Grammar, and vocabulary and sentence structure to draw the attention of the SSEs to the importance of pronunciation in learning English.

- Difficulty of production should not be too great because the above consonant sounds are produced at the front of the mouth; this motor skill is not too difficult to learn. For practicing, correcting and developing the pronunciation error we strongly suggest for the SSEs to listen regularly to English sounds and words using audio aids like cassettes, CDs and sound dictionaries. These tools are very useful for practicing pronunciation.

- I think it is also worth looking at the dictionary for checking the correct pronunciation of words.

- It is advised that the teachers in pre-university stages have good knowledge of phonetics and phonology because this will provide a basis for teachers to pronounce a word correctly and identify the physical reasons for inaccurate approximations of foreign language sounds, enabling them to give precise instructions which help SSEs correct, faulty pronunciation.

\section{Acknowledgments}

I gratefully acknowledge my deep indebtedness to all my teachers and colleagues who helped me in this study. Particularly, I wish to express my thanks to professor Abdul Wahab Abbashar (Khartoum University) for his guidance and supervision throughout this study.

My sincere thanks also go to Mr. Ted Power (Language Centre, London) for supporting with relevant materials to the research, Dr. Sultan Daud, from Pakistan, (Ph.D linguistics) who edited my work Dr. Bassam (from Iraq) at Sudan University of Science and Technology, who conducted the statistical treatments, Dr. Abbakar Ali for helping me to do the statistical part of the study. I must acknowledge as well the many friends, colleagues ,teachers ,students and librarians who assisted ,advised and supported my research and writing efforts over the years .

My thanks are extended to English Language teaching staff at Sudan University of Science and Technology.

\section{References}

Akande, A. T. (2005). The Pronunciation Problems in The English of Some Yoruba Learners. Retrieved from http://www.hkjtefl.org/2005-Akande-Yoruba.pdf

Alkhuli, M. A. (1983). English as a Foreign Language. Ph.D Dissertation, King Abdul Aziz Public Library.

Baker, A. (1981). Ship or Sheep (2nd ed.). Cambridge University Press.

Baker, A. (1981). Tree or Three? Cambridge University Press.

Brown, H. D. (2000). Principles of Language Learning and Teaching (4th ed.). Longman: Sanfrancisco State University.

Carter, J. C. (1977). Fundamental Problems in Phonetics. Edinburgh: Edinburgh University Press.

Carter, R., \& Nunan, D. (2001). The Cambridge Guide to Teaching English to Speakers of Other Languages. Cambridge: Cambridge University Press. http://dx.doi.org/10.1017/CBO9780511667206

Gimson, A. C., \& Crutteden, A. (1994). Gimson's Pronunciation of English. London: Edward Arnold. 
Homidan, A. H. (1984). Utilizing the Theory of Articulatory Settings in the Teaching of English Pronunciation to Saudi Students Learning English as a Second Language. Doctoral Dissertation, King Fahd Public Library.

Jones, D., Roach, P. J., \& Hartman, J. (1997). Daniel Jones English Pronouncing Dictionary (15th ed.). Cambridge: Cambridge University Press.

Ladefoged, P. (2001). A Course in Phonetics, 4th ed., Heinle and Heinle. Los Angles: University of California.

Moosa, M. H. (1979). Difficulties of Learning the Pronunciation and Structural Differences Between Arabic and English. MA Dissertation, Library of Saudi Arabia, Educational mission; Texas.

O’Connor, J. D. (1980). Better English Pronunciation (2nd ed.). Cambridge: Cambridge University Press.

Roach, P. (2003). English Phonetics and Phonology (3rd ed.). Cambridge: Cambridge University Press.

Swan, M., \& Smith, B. (2001). Learner English: A Teacher's Guide to Interference and Other Problems. Cambridge: Cambridge University Press. http://dx.doi.org/10.1017/CBO9780511667121

Yule, G. (1996). The Study of Language (2nd ed.). Cambridge: Cambridge University Press.

\section{Appendix A}

\section{Frequency Distribution of Research Items}

\begin{tabular}{|c|c|c|c|c|}
\hline No & Item & Agree & Not sure & Disagree \\
\hline 1 & $\begin{array}{l}\text { Do you think Sudanese students of English (SSE) pronounce /f/ instead of /V/ in } \\
\text { words like "have", "van", "marvel". }\end{array}$ & 21 & 2 & 7 \\
\hline 2 & Most of the SSE pronounce /b/ instead of /p/ in words like "pen", "map", "happy". & 28 & - & 2 \\
\hline 3 & $\begin{array}{l}\text { Some of the SSE pronounce /s/ instead of / } \theta / \text { in words like "think", "math", } \\
\text { "mathematics". }\end{array}$ & 26 & 3 & 1 \\
\hline 4 & Many SSE pronounce / $/ /$ instead of $/ \mathrm{t} \int /$ in words such as "much", "furniture". & 18 & 1 & 11 \\
\hline 5 & Some SSE pronounce /dz/ in the place of /g/ in words such as "engagement". & 20 & 2 & 8 \\
\hline 6 & Some SSE pronounce /z/ instead of /ð/ in words like "then", "weather". & 25 & 1 & 4 \\
\hline 7 & $\begin{array}{l}\text { Many SSE pronounce /gh/ as / / / instead of /f/ in words such as "cough", "rough", } \\
\text { "enough". }\end{array}$ & 19 & 4 & 7 \\
\hline 8 & Some SSE pronounce /k/ instead of /s/ in words like "concern". & 15 & 5 & 10 \\
\hline 9 & Many SSE pronounce /ei/ instead of /ə/ in words like "obstacle". & 14 & 8 & 8 \\
\hline 10 & Most of the SSE pronounce /ai/ in the place of /1/ in words like "service ". & 14 & 1 & 15 \\
\hline 11 & $\begin{array}{l}\text { Some SSE pronounce } / \mathrm{\rho} / \text { instead of } / \mathrm{a} / \text { in words such as "pronunciation", } \\
\text { "income". }\end{array}$ & 22 & 3 & 5 \\
\hline 12 & Most of the SSE pronounce / / / or /u/ instead of /ju:/ in words such as "tutor". & 18 & 7 & 5 \\
\hline 13 & $\begin{array}{l}\text { Some of the SSE pronounce /e/ instead of /i/ in words like "experience", } \\
\text { "women". }\end{array}$ & 19 & 3 & 8 \\
\hline 14 & $\begin{array}{l}\text { Some SSE pronounce /ei/ instead of / } / \text { in words such as "also", "fall" because } \\
\text { each vowel has more than one pronunciation. }\end{array}$ & 16 & 5 & 9 \\
\hline 15 & $\begin{array}{l}\text { Many SSE replace } / \theta / \mathrm{by} / \mathrm{s} /, / \mathrm{d} / \text { by } / \mathrm{z} / \\
/ \mathrm{p} / \text { by } / \mathrm{b} / \text { because } / \theta /, / \mathrm{d} /, / \mathrm{p} / \text { do not exist in Sudanese spoken Arabic. }\end{array}$ & 24 & 3 & 3 \\
\hline 16 & $\begin{array}{l}\text { SSE fail to pronounce final "gh" as If! in words like "cough", "rough" because } \\
\text { they do not know the relationship between letter and sound. }\end{array}$ & 25 & 3 & 2 \\
\hline
\end{tabular}


17 SSE replace /g/ by /dz/ as in "engagement" because this sound is inconsistent.

24

17

24 between Arabic language and English language.

20 SSE mispronunciation some English sounds, because they predict the pronunciation from the spelling.

21 Do you think looking up words in the dictionary help the SSE improve their English pronunciation.

22 Do you think listening to the English sounds and words in audio aids (tape, CD, 28 TV channels) help improve students' pronunciation.
5

5

27

25

4

\section{Copyrights}

Copyright for this article is retained by the author(s), with first publication rights granted to the journal.

This is an open-access article distributed under the terms and conditions of the Creative Commons Attribution license (http://creativecommons.org/licenses/by/3.0/). 